\title{
A Study on the Application of College English PBL Teaching Mode in the Multimedia Environment
}

\author{
Wei Yin \\ Jilin Engineering Normal University, Changchun, China \\ 2238552865@qq.com
}

\begin{abstract}
Keywords: PBL mode; College English; Teaching mode; Multimedia environment
\end{abstract}
\begin{abstract}
PBL mode is a new type of teaching mode based on the learning theory of constructivism. It acquires new knowledge by oneself or through cooperation among students, maximizes the autonomy of students' learning and helps develop students' abilities of finding, raising and solving problems. So the learning enthusiasm of students is greatly improved. The PBL teaching mode transforms the teacher from the teaching subject to the instructor, and the students are transformed from the passive knowledge recipient to the active learners. To research PBL teaching mode can not only broaden the teaching ideas and teaching methods, but also can improve the teaching efficiency. To make full use of the positive role of PBL mode, it will guarantee the implementation of quality education and cultivation of all-round development of talents.
\end{abstract}

\section{Introduction}

The current college English teaching is in the transitional period, the unified normative teaching is developing to the diversified teaching modes. The traditional college English teaching has been centered on the teaching of linguistic points, grammar and sentence patterns. The problem of this kind of changeless fundamental English orientation is the traditional examination-oriented education and the general slackness of learning, so that the students are basically in the passive condition. Teachers can not take into account the individual differences of students, so some students are suppressed, which makes them low interest in learning, their learning autonomy and ability of language application are weak. The PBL teaching mode considers the students as the main body, emphasizing the autonomy of students and the importance of self-study, so that students fully aware of the goal of college English learning is not a test but application. PBL mode enhances students' sense of self-participation and self-evaluation, which makes students who do not like speaking have chances to participate in classroom activities, so that the interaction between teachers and students, or even among students, becomes meaningful, thereby stimulating the learning enthusiasm of students.

\section{The Connotation and Necessity of PBL Teaching Mode}

PBL is known as problem-based learning, which the earliest originated from medical education in 1950s. In 1969, the American neurologist Professor Barrows first mentioned in Canada. American scholar Hallinger and Bridges noted the great potential of PBL mode and its value in the field of education; they launched a lot of researches and gradually applied to the field of education. China's research on PBL mode began in the 1990s, the initial researchers were mainly used to translate foreign literatures and monographs to understand or recognize the PBL teaching mode, and then gradually tried to explore the application of PBL mode to teaching practice and curriculum design.

The PBL mode is a student-centered educational mode, which emphasizes people-oriented educational thinking. Compared with the traditional teaching mode, teachers can understand and attach importance to individual differences and personality characteristics in the teaching process with the aim of guiding and arranging learning tasks better. PBL mode highlights the students' manual dexterity and develops their effective problem-solving abilities and lifelong learning skills. In this problem-based mode, students are transformed into effective collaborators, who will solve real problems through cooperation among learners and improve learning effects. While improving the 
students' language proficiency, which is also in line with the requirements of students' application abilities during the background of the current application-oriented university transformation.

\section{The Application of the PBL Teaching Mode}

To take PBL teaching mode and college English teaching practices into consideration, the teaching practice is divided into three stages - preliminary stage of the mode, in the process of the mode and later stage of the mode. At first, teachers should introduce learning characteristics and scoring criteria of the PBL mode to students. According to the nature of the course and curriculum content, we should form several learning groups with the combination of learners' characteristics. The author taught an experimental class, which was divided into five groups, each group of eight students. We can counterpoise English comprehensive skills of students in each group, and strive to let students help each other. And based on the relevant theory of PBL teaching mode, construct PBL teaching mode, and carry out case design and implement step by step.

Preliminary Stage of the Mode. It is time to impart knowledge and raise questions. The instructor explains the teaching subject and learning questions of each unit, instructs the students to proceed with the study of the subject, and makes suggestions to the student's learning plan. This stage is not subject to the restrictions on time, teachers can also communicate with students in the multimedia environment or through the WeChat, Moso Teach and other learning apps after class and add learning tasks at any time.

In the Process of the Mode. This is the process of students' knowledge internalization. Autonomous learning is the beginning of solving the problem, the students will explore the collaborative learning problems, and the data were collected, collated, analyzed, summarized, given feedback and discussed by the group members. They will complete the learning content all together, it creates a relatively relaxed learning atmosphere to students, and to increase students' opportunities for English communication, and then improve learning efficiency. At this stage, teachers should focus on cultivating students' awareness and ability of collaborative learning, which is also required by students when they are going to work.

Later Stage of the Mode. It is the process of further internalization. To show the results of learning via PPT or videos and other forms of reporting by the students, the teacher will evaluate the results. During the process, teacher and students will make feedback together. Students can give mutual assessment, which is based on their respective completing task in the group, so as to avoid some students' passive lazy learning, and ultimately to record the score in formative evaluation.

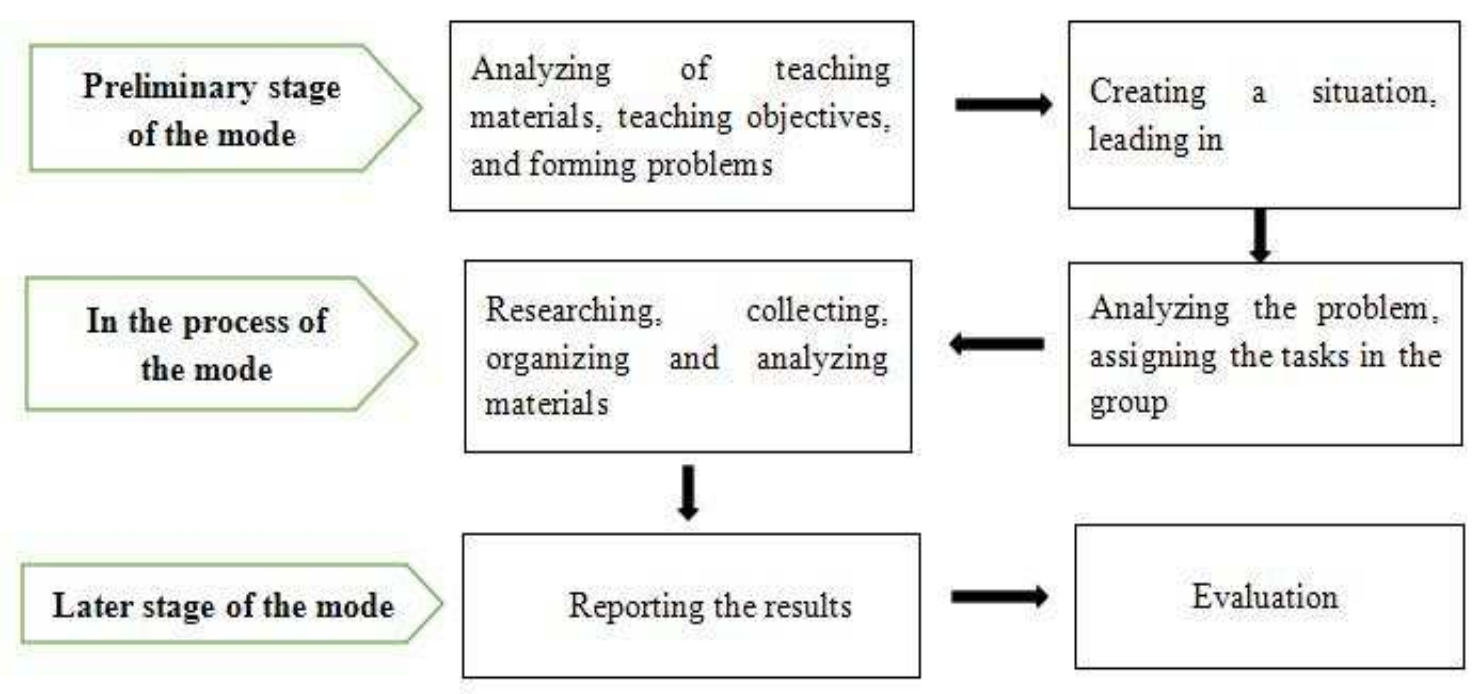

Figure 1. The implementation process of the PBL teaching mode 
In this teaching mode, due to a combination of group learning and participant-oriented problems building, students' co-writing, cognition and collaboration will be strengthened at the same time. In addition, students will take the initiative to choose, discuss and solve specific questions by using the knowledge gained in the teaching mode. The team works together to complete one project process ,which provides an excellent discussion platform for the students. In thinking about technology, humanities and society, even the topics of environmental protection, social responsibility, and cultural diversity are frequently discussed. They will broaden their horizons.

The PBL teaching mode based on cooperative learning is effectively reduced the students' sense of anxiety, which provides a relaxing and comfortable psychological environment to learn a foreign language. Besides, PBL teaching mode which is based on problem-solving transforms students from the passive learning to a positive discovery style of learning, thereby enhancing their interests in learning and motivation for discovering. Also it provides a steady stream of motivation of second language acquisition. After a semester of implementing PBL mode, the author interviewed some students who has poor English grounding. They held positive attitudes that they had mastered more words; it gave them a broad show stage and full of challenges; their oral English has improved a lot.

\section{Advantages of PBL Teaching Mode in College English Teaching}

As we know, teaching process includes "teaching" and "learning" which interacts between teacher and students. The traditional teaching mode that was centered on "teaching" considered the teacher as the center. During this single teaching mode, students passively received knowledge, lacking of autonomy, creativity and so on. Although this teaching method is easy to teach, manage, organize or supervise classroom teaching, it ignores the students' cognition which plays the main role and the ability to apply the language learning. They had no team cooperation. In contrast, the PBL teaching mode is available in college English teaching, it has the following advantages:

PBL Mode is Suitable for the Characteristics of Language Teaching. Using PBL teaching mode, it regards the problem as a stimulator to learning, rather than the previous learning materials to learn new contents.[6] According to the theme of the learning content, teachers can set a variety of real, open and meaningful questions and realistic situation which are similar to the learning scene. PBL teaching mode in the multimedia environment provides an effective way to create natural real context. The curiosity which is aroused by problems will inspire them use knowledge to search for questions. This kind of learning activities is placed in various real communication environments. It helps students understand the effectiveness and practicality of learning and motivate learning initiatives.

PBL Mode Helps Develop Students' Learning Autonomy. In the PBL teaching mode, the teacher's primary responsibility is not the knowledge communicators, but promoters, managers, supervisor and guides. Students have more autonomy; they decide what they need to learn and how to learn. In the process of preparation, completion of the tasks, their self-learning ability has improved. In order to complete the task, students need to make independent research, and conduct self-guidance. The process of solving the problem will greatly help to learn the cultivation of autonomy and the abilities of lifelong learning. This will be well prepared for their learning and working in the future. The job in preparation phase can train the ability of using literature reviews, accessing books and online materials, which will be important for their future careers.

PBL Mode Can Develop Students' Emotional Abilities. Since the PBL mode is based on the "group" as the center, thus it is helpful for the training the spirit of collaboration and collaborative skills. In order to make the project completed successfully, it should play the role of everyone. The group members must encourage each other and learn how to communicate well. Through the group discussion, mutual evaluation, mutual encouragement, mutual help, students establish the cooperative and competitive relationships, and to strive for opportunities of knowledge construction at the same time. PBL mode enhances students' self-participation consciousness and self-worth consciousness. Students who are introverted and do not love speaking will have the opportunity to attend class 
activities. These meaningful interactions between teachers and students, or even between students, inspire students to learn enthusiastically.

PBL Mode Helps Teachers Grasp the Teaching Effects in a Timely and Accurate Manner. The solution to the problem is the best way to make feedback on teaching. By showing students' achievements, the teacher can get the idea of students' understanding the extent of what they have learned. So as to the teacher adjust the teaching methods or strategies timely. Thus students will more actively participate in learning activities.

\section{Reflections on PBL Teaching Mode}

Firstly, the homogeneity of thinking from the learning group members in PBL mode of the classroom setting is higher, so the overall level of thinking is difficult to reach a higher level, which also determines the designs of final problem solution lack of a higher level of innovation. Secondly, the PBL teaching mode puts forward higher requirements to the teachers' abilities. Teachers not only have an in-depth understanding of the curriculum knowledge, but also have to dabble in the relevant contents of the released research questions in order to guide students how to analyze the problems and solve the problem better. Thirdly, under the current system of large-scale teaching, the PBL teaching mode obviously takes more time. Teachers need to pay more energy and patience in guiding and evaluating the students' self-learning. In particular, compared with the traditional summative evaluation, PBL mode has many forms of feedback which includes the teacher's evaluation of students, students' mutual evaluation, as well as summary of the questions. It puts forward higher requirements to PBL mode. These are demanded urgent solutions by educational institutions, teaching researchers and front-line teachers in the process of continuous teaching practices.

\section{References}

[1] Barrows, H.S.: Practice-Based Learning: Problem-Based Learning Applied to Medical Education (Southern Illinois University School of Medicine, United States of America 1994).

[2] Bridges, E., Hallinger, P.: Problem Based Medical and Managerial Education (Teachers College Press, United States of America 1995).

[3] D.F. Shu: FLT in China: Problems and Suggested Solutions (Shanghai Foreign Language Education Press, China 2004).

[4] [4] X.Y. Du, A. Kolmos and J.E. Holgaard: Research in Higher Education of Engineering, Vol. 116 (2009) No.3, p.29-35.

[5] L. Li, J.M. Du: Foreign Language Education, Vol. 35 (2014) No.5, p.55-58.

[6] Y. Yang, X.H. Zhong: Journal of Chengdu University of TCM(Educational Science Edition), Vol. 12 (2010) No.2, p.48-49.

[7] X.D. Chen: Journal of PLA University of Foreign Languages, Vol. 36 (2013) No.4, p.68-72

[8] L.H. Chen, A.F. Deng: Distance Education in China, Vol. 380 (2010) No.11, p.46-48.

[9] Y.S. Yin: The Applied Research of PBL Teaching Mode in Practice Courses of Educational Technology (M.A., Shandong Normal University, China 2014). 